\title{
Late preterm birth in the far south of Brazil: a population based study
}

\author{
Adriana Kramer Fiala Machado 1 \\ Luana Patrícia Marmitt 2 \\ Juraci Almeida Cesar 3
} 1-3 Programa de Pós-graduação em Ciências da Saúde. Faculdade de Medicina. Universidade Federal do Rio Grande. Rio Rua Visconde de Paranaguá, 102. Rio Grande, RS,
Brasil. CEP: 96.200-190. E-mail: drikramer@hotmail.com

\begin{abstract}
Objectives: to describe the prevalence of late preterm birth (LPB) and identify factors associated with its occurrence in the municipality of Rio Grande, RS.

Methods: a standardized questionnaire was applied to all puerperal women resident in the municipality who had children in the year 2013. Preterm birth was defined as birth occurring between the $34^{\text {th }}$ and $36^{\text {th }}$ week of gestation, preferably evaluated by means of ultrasonography in the $6^{\text {th }}$ to $20^{\text {th }}$ weeks. The analysis used Poisson regression with robust adjustment of variance, following the hierarchical model.The effect measure used was the prevalence ratio $(P R)$.

Results: of the 2286 births included in the study, 11.8\% (CI95\%: 10.5-13.1) were LPBs. After adjusted analysis, the PRfor occurrence of LPB among black-skinned motherswas 1.40 (1.01-1.96) in relation to white-skinned women; 1.74 (1.23-2.45) among those who attended less than six prenatal consults compared to those who attended nine or more; the PR was 1.36 (1.11-1.68) for those classified as depressives compared to others and 1.29 (1.01-1.65) for those undergoing caesarian.

Conclusions: the results suggest the existence of inequality in relation to skin color and the important impact of the number of prenatal consults on the outcome. More appropriately designed studies are needed to confirm the causal relation among maternal depression, caesarian and $L P B$.
\end{abstract}

Key words Premature birth, Gestational age, Prevalence, Risk factors 


\section{Introduction}

One in every ten births around the world occurs prior to completion of the $37^{\text {th }}$ week of gestation. ${ }^{1}$ These children are preterm and, as a result, account for $35 \%$ of neonatal deathsandrepresent the second most common cause of death among those aged under five years. ${ }^{1}$ The occurrence of preterm varies, with prevalences of 5\% in Europe and $18 \%$ in Africa. ${ }^{2}$ In Brazil, in 2011, the rate was $11.8 \%$, one of the ten highest in the world.2,3

Around $70 \%$ of preterm babiesare born between the $34^{\text {th }}$ and $36^{\text {th }}$ week of gestation, ${ }^{4}$ a period classified as late preterm. ${ }^{5}$ The newborns from this period are more likely to present respiratory diseases, necrotizing enterocolitis, sepsis, hyperbilirubinema and feeding difficulties. ${ }^{6}$ Furthermore, the risk of death of late preterm babies in the first year of life is around three times greater compared to term babies. $1,5,7,8$

Between 1990 and 2010, the occurrence of late preterm births doubled around the world from 5.0\% to $10.0 \%, 2,7$ with the exception of the United States, where, there was a fall from $6.9 \%$ to $5.8 \%$ after 2005.1,9 Data for Brazil is scarce and there are no estimates for the country as a whole. In Pelotas, in the South region, the rate of late preterm births was $11.0 \%$ in 2004,10 while, in the city of São Paulo, in the Southeast region, the prevalence rose from $8.0 \%$ in 2004 to $10.6 \%$, in 2010.8 Possible reasons for this increase are the growing number of caesarians, new fertilization methods, with a consequent increase in the number of multiple gestations and the number of pregnant women aged over 35 years. $7,8,10,11$

Studies of this subject are clearly scarce in Brazil, principally in the smaller municipalities. This hinders the identification of risk and protection factors and thus the establishment of measures to prevent the occurrence of late preterm births. The present study aimsto estimate the prevalence of late preterm and to identify factors associated with its occurrence among newborns in the municipality of Rio Grande, RS, in 2013.

\section{Methods}

The municipality of Rio Grande has around 200,000 inhabitants and is located in the far South of the State of Rio Grande do Sul, around $300 \mathrm{~km}$ from the State capital, Porto Alegre. ${ }^{11}$ In 2012, its Human Development Index (HDI) was 0.74 and its per capita Gross Domestic Product (GDP) R \$ 45,000.12 In the same year, the child mortality coefficient was
13.5 per thousand live births. 12 Among the 18 municipalities in the State with a population of more than 100,000 , it ranked $15^{\text {th }}$ in terms of the best health indicators in the same year. ${ }^{12}$

This prevalence study was conducted in the only two maternity hospitals in the municipality, between 1 January and 31 December 2013. The study covered all puerperal women resident in the urban or rural areaswho had a single birth and completed at least 34 full weeks of gestation.

The sample size was calculated on the basis of an estimated prevalence of late preterm birth of $10 \%$, a margin of error of 1.3 percentage points, a level of significance of $95 \%$ and an added $5 \%$ to cover losses. Based on these parameters, the study should include at least 2144 women. In terms of identification of associated factors, the variable that required the largest sample had the following parameters: alpha error 0.05 , beta error 0.20, nonexposed/exposed ratio of $85 / 15$, prevalence of outcome in non-exposed of $9.8 \%$ and prevalence ratio of 1.8. At least 2247 women should thus be included in the study. This number already includes an added $15 \%$ to control forpotential confounding factorsand $3 \%$ for losses.

All the information for the study was obtained by applying a single questionnaire to women up to 48 hours after childbirth. The questionnaire was designed to collect information on demographic characteristics (age in full years -13 - 19, 20 - 29, 30 or over; skin color as observed by the interviewerwhite, mixed raceandblack), socioeconomic status (household income - in terciles), reproductive history (prior preterm birth - none, oneandtwo or more), lifestyle (physical exercise during gestation no, yes and stopped and yes and didn't stop), morbidity during gestation (depression - yes or noand treated - yes or no), care during pregnancy and childbirth (month of first prenatal session- $1^{\text {st }}$ trimester, $2^{\text {nd }}$ trimesterand $3^{\text {rd }}$ trimester; number of prenatal consults $-0-5,6-8$ and 9 or more; kind of birth - vaginal or caesarian). Information on gestational age was also copied from the Pregnancy Card onto the standard form (ultrasound, month of gestation in which conducted and date of last menstruation).

Gestational age was determined by ultrasound between the $6^{\text {th }}$ and $20^{\text {th }}$ week of gestation. This method, which is the most accurate, was chosen for estimating gestational age.13,14 In the absence of this, the date of last menstruationnoted on the Pregnancy Card was used and, as a last resort, the date of last menstruation reported by the interviewee immediately after giving birth. 
Late preterm birth was defined as birth occurring between the $34^{\text {th }}$ and $36^{\text {th }}$ week of gestation, as proposed in 2005 by theNational Institute of Child Health and Human Development of the National Institute of Health. ${ }^{5}$

Four interviewers were selected and trained to conduct the investigation. A pilot study was carried out in the first fortnight of December 2012 at both maternity hospitals. During data collection, the interviewers visited the hospitals dailyidentifying each woman giving birth by way of information on hospital admissions forms, followed by her identification in the hospital and a visit to the wards. The questionnaire was applied only after the mother had given her consent and signed two copies of a Term of Free and Informed Consent, one of which stayed with the mother.

The questionnaires applied were codified, typed in duplicate by separate individuals in inverse order, using Epidata 3.1 free software. These copies were comparedand errors listed and corrected. At the end of this stage, the data were put together into a bank for labelling and creation of variables using the Stata Version 13 statistics program, which was also used for further analysis. Finally, the data obtained were comparedin terms of absolute number of births with information from the Ministry of Health's Live Births (SINASC) and Mortality (SIM) Information Systems. 15

Quality control was performed by repeating 7\% of the interviews with the mothers, by telephone, using a reduced questionnaire containing key questions from the one applied in the hospital. The Kappa index varied from 0.63 to 0.78 , indicating moderate to satisfactory concordance.

The descriptive analysis was carried out by obtaining the frequency listing for the outcome and independent variables. Raw and adjusted analyses of factors associated with the outcome, late preterm birth, used Poisson regression with robust adjustment of variance. The outcome measurement was expressed as the prevalence ratio (PR), a 95\% confidence interval (CI95\%) and $p$ value of the line of best fit test for ordinal variables and the Wald heterogeneity test for other variables.

For adjusted analysis, a four-level (or block) hierarchical model was drawn up to determine the order of entry of variables into the model. The first level included the maternal demographic and socioeconomic variables (age, skin colorand monthly household income); the second level, characteristics of reproductive life (parity - number of living children; and deaths and number of previous preterm pregnancies); the third level variables relating to care during pregnancy and childbirth (trimester of first and number of prenatal consults, gestational morbidities and type of birth); and the fourth level variables relating to lifestyle and behavior of the mother (physical exercise). Morbidity during the gestational period was taken to be any report of illness originating during pregnancy that received medical treatment; and physical exercise considered only activities performed for leisure.

In the (backward) regression model used, all the variables of the first hierarchical level were introduced and those with a $p$ value $>0.20$ subsequently excluded. The second level variables were adjusted for all those of the same level plus those of the previous level whose $p$ value was $\leq 0.20$. This procedure was repeated for the other levels. The statistical association between the independent variables and the outcome was evaluated using the confidence interval of $95 \%$ of the measure of association, which, in this case, was the prevalence ratio.

The research project was approved by the Research Ethics Committee for Health (CEPAS) of the Federal University of Rio Grande (process: 2623/2012-17).

\section{Results}

According to the SINASC and the SIM, in 2013, there were 2761 births to mothers living in the municipality of Rio Grande. It was possible to obtain information on 2685 of these, a response rate of $97.2 \%$. As the gestational age was obtained for 2504 of theseand the present study included only live single births with at least 34 weeks of gestation, the final sample comprised 2286 newborns.

Half of the women studiedwere aged between 20 and 29 years, $66.8 \%$ were whiteand $54.5 \%$ received a monthly income of between one and two minimum wages. Of those interviewed, $7.2 \%$ had already experienced at least one preterm pregnancy; $79.1 \%$ began prenatal consults in the first trimester of gestation and $87.5 \%$ had attended at least six sessions; most (62.9\%) underwent caesarian; and 3.9\% reported medically treated depression during pregnancy. Around one third (32.7\%) practicedsome kind of regular physical activity during pregnancy. Gestational age was estimated using ultrasound in $78.3 \%$. The rate of late preterm birth was $11.8 \%$ (Table 1).

Table 2 showsthe prevalence of late preterm birth per category of variable included in each level and the raw and adjusted analyses. The rate of late preterm birth varied from $9.0 \%$ among mothers who exercised throughout pregnancy to $22.6 \%$ among 
those with a history of two or more preterm pregnancies.

After adjusted analysis, respecting the entry of each variable by level to which it belongs, as previously described in the Methods section, the following variables remained significantly associated with the outcome: skin color, number of prenatal consults, depression during pregnancy and type of birth. Black mothers had PR=1.40 (CI95\%: 1.01-1.96) in relation to white mothers; attending less than six prenatal consults had $\mathrm{PR}=1.74$ (CI95\%: 1.23-2.45), a higher figure compared to nine or more consults; depressive pregnant women had $\mathrm{PR}=1.36$ (CI95\%: 1.11-1.68) in relation to the others; those who underwent caesarian had PR=1,29 (CI95\%: 1.01-1.65) compared to vaginal births.

\section{Table 1}

\begin{tabular}{|c|c|c|c|c|c|c|}
\hline \multirow[t]{2}{*}{ Variable } & \multicolumn{2}{|c|}{ Late preterm } & \multicolumn{2}{|c|}{ At term } & \multicolumn{2}{|c|}{ Total * } \\
\hline & $\mathrm{n}$ & $\%$ & $\mathrm{n}$ & $\%$ & $\mathrm{n}$ & $\%$ \\
\hline Age of mother (years) & & & & & \multicolumn{2}{|c|}{$p=0.098$} \\
\hline $13-19$ & 41 & 15.2 & 356 & 17.7 & 397 & 17.4 \\
\hline $20-29$ & 127 & 47.0 & 1028 & 50.9 & 1155 & 50.5 \\
\hline 30 or over & 102 & 37.8 & 632 & 31.4 & 734 & 32.1 \\
\hline Skin color & & & & & \multicolumn{2}{|c|}{$p=0.074$} \\
\hline White & 164 & 60.7 & 1363 & 67.6 & 1527 & 66.8 \\
\hline Mixed race & 69 & 25.6 & 436 & 21.6 & 505 & 22.1 \\
\hline Black & 37 & 13.7 & 217 & 10.8 & 254 & 11.1 \\
\hline Household income in terciles & & & & & \multicolumn{2}{|c|}{$p=0.211$} \\
\hline First (lowest) & 85 & 31.5 & 667 & 33.1 & 752 & 32.9 \\
\hline Second & 86 & 31.8 & 714 & 35.4 & 800 & 35.0 \\
\hline Third (highest) & 99 & 36.7 & 633 & 31.4 & 732 & 32.1 \\
\hline Number of previous preterm pregnancies & & & & & \multicolumn{2}{|c|}{$p=0.134$} \\
\hline None & 245 & 90.7 & 1878 & 93.1 & 2123 & 92.9 \\
\hline 1 & 18 & 6.7 & 114 & 5.7 & 132 & 5.8 \\
\hline 2 or more & 7 & 2.6 & 24 & 1.2 & 31 & 1.4 \\
\hline Trimester of first neonatal session** & & & & & \multicolumn{2}{|c|}{$p=0.045$} \\
\hline First & 195 & 73.8 & 1593 & 79.7 & 1788 & 79.1 \\
\hline Second & 62 & 23.5 & 377 & 18.9 & 439 & 19.4 \\
\hline Third & 7 & 2.7 & 27 & 1.4 & 34 & 1.5 \\
\hline Number of prenatal consults & & & & & \multicolumn{2}{|c|}{$p=0.002$} \\
\hline $0-5$ & 49 & 18.6 & 234 & 11.7 & 283 & 12.5 \\
\hline 6 or more & 215 & 81.4 & 1764 & 88.3 & 1979 & 87.5 \\
\hline Kind of birth & & & & & \multicolumn{2}{|c|}{$p=0.168$} \\
\hline Vaginal & 90 & 33.3 & 759 & 37.6 & 849 & 37.1 \\
\hline Caesarian & 180 & 66.7 & 1257 & 62.3 & 1437 & 62.9 \\
\hline Depression during pregnancy & & & & & \multicolumn{2}{|c|}{$p=0.005$} \\
\hline Yes and treated & 19 & 7.0 & 71 & 3.5 & 90 & 3.9 \\
\hline No & 251 & 93.0 & 1945 & 96.5 & 2196 & 96.1 \\
\hline Physical exercise during pregnancy & & & & & \multicolumn{2}{|c|}{$p=0.055$} \\
\hline No & 191 & 70.7 & 1344 & 66.7 & 1535 & 67.2 \\
\hline Yes, but stopped & 31 & 11.9 & 194 & 9.7 & 226 & 9.9 \\
\hline Yes, and did not stop & 47 & 17.4 & 476 & 23.6 & 523 & 22.9 \\
\hline Method for determining gestational age & & & & & \multicolumn{2}{|c|}{$p=0.040$} \\
\hline Ultrasound (6th $-20^{\text {th }}$ week) & 198 & 73.3 & 1591 & 78.9 & 1789 & 78.3 \\
\hline Date of last menstruation, pregnancy card & 11 & 4.1 & 94 & 4.7 & 105 & 4.6 \\
\hline Reported date of last menstruation & 61 & 22.6 & 331 & 16.4 & 392 & 17.2 \\
\hline Total & 270 & 11.8 & 2016 & 88.2 & 2286 & 100.0 \\
\hline
\end{tabular}

*The $p$ value presented refers to the chi-squared test; **Data for 2261 pregnant women performed prenatal care. 
Table 2

Prevalence (\%) of late preterm birth and prevalence ratios (raw and adjusted) by maternal characteristics. Rio Grande, RS, $2013(n=2.286)$.

\begin{tabular}{|c|c|c|c|c|}
\hline \multirow[t]{2}{*}{ Level } & \multirow[t]{2}{*}{ Variable } & \multirow{2}{*}{$\begin{array}{l}\text { Prevalence of late } \\
\text { preterm birth \% }\end{array}$} & \multicolumn{2}{|c|}{ Prevalence ratio (CI95\%) } \\
\hline & & & Raw & Adjusted \\
\hline \multirow[t]{12}{*}{1 st } & Age of mother (years) & & $p=0.097$ & $p=0.221$ \\
\hline & $13-19$ & 10.3 & 1.00 & 1.00 \\
\hline & $20-29$ & 11.0 & $1.06(0.76-1.49)$ & $1.06(0.76-1.49)$ \\
\hline & 30 or over & 13.9 & $1.34(0.95-1.89)$ & $1.29(0.90-1.85)$ \\
\hline & Skin color & & $p=0.073$ & $p=0.043$ \\
\hline & White & 10.7 & 1.00 & 1.00 \\
\hline & Mixed race & 13.7 & $1.27(0.98-1.65)$ & $1.31(1.00-1.70)$ \\
\hline & Black & 14.6 & $1.36(0.97-1.89)$ & $1.40(1.01-1.96)$ \\
\hline & Household income in terciles & & $p=0.200$ & $p=0.322$ \\
\hline & First (lowest) & 11.3 & 1.00 & 1.00 \\
\hline & Second & 10.7 & $0.95(0.72-1.26)$ & $0.95(0.72-1.27)$ \\
\hline & Third (highest) & 13.5 & $1.20(0.91-1.57)$ & $1.17(0.88-1.56)$ \\
\hline \multirow[t]{4}{*}{$2^{\text {nd }}$} & Number of previous preterm pregnar & ncies & $p=0.113$ & $p=0.128$ \\
\hline & None & 11.5 & 1.00 & 1.00 \\
\hline & 1 & 13.6 & $1.18(0.76-1.84)$ & $1.14(0.73-1.78)$ \\
\hline & 2 or more & 22.6 & $1.96(1.01-3.79)$ & $1.93(1.00-3.71)$ \\
\hline \multirow[t]{14}{*}{$3 r d$} & Trimester of first neonatal session** & & $p=0.040$ & $p=0.351$ \\
\hline & First & 10.9 & 1.00 & 1.00 \\
\hline & Second & 14.1 & $1.29(0.99-1.69)$ & $1.11(0.83-1.50)$ \\
\hline & Third & 20.6 & $1.89(0.96-3.70)$ & $1.59(0.81-3.13)$ \\
\hline & Number of prenatal consults & & $p=0.001$ * & $p=0.005^{*}$ \\
\hline & $0-5$ & 17.9 & $1.73(1.28-2.32)$ & $1.74(1.23-2.45)$ \\
\hline & $6-8$ & 11.5 & $1.11(0.86-1.43)$ & $1.15(0.89-1.50)$ \\
\hline & 9 or more & 10.4 & 1.00 & 1.00 \\
\hline & Kind of birth & & $p=0.170$ & $p=0.047$ \\
\hline & Vaginal & 10.6 & 1.00 & 1.00 \\
\hline & Caesarian & 12.5 & $1.18(0.93-1.50)$ & $1.29(1.01-1.65)$ \\
\hline & Depression during pregnancy & & $p=0.004$ & $p=0.003$ \\
\hline & No & 11.4 & 1.00 & 1.00 \\
\hline & Yes and treated & 21.1 & $1.36(1.10-1-67)$ & $1.36(1.11-1.68)$ \\
\hline \multirow[t]{4}{*}{$4^{\text {th }}$} & Physical exercise during pregnancy & & $p=0.06$ & $p=0.073$ \\
\hline & No & 12.4 & $1.38(1.02-1.87)$ & $1.32(0.98-1.79)$ \\
\hline & Yes, but stopped & 14.2 & $1.58(1.03-2.40)$ & $1.61(1.05-2.47)$ \\
\hline & Yes, and did not stop & 9.0 & 1.00 & 1.00 \\
\hline
\end{tabular}

*Linear tendency test; **Data for 2261 pregnant women performed prenatal care.

Adjustments per level (block):

Level 1: Age of mother, skin color and household income;

Level 2: Equation $1+$ previous preterm birth;

Level 3: Equation 2 + trimester of first prenatal session, number of prenatal consults, type of birthanddepression during pregnancy

Level 4: Equation 3 + physical exercise during pregnancy.

\section{Discussion}

At least one in ten newborns were late preterm births in the municipality of Rio Grande in 2013. The occurrence of this was significantly associated with black mothers, those who reported depression during pregnancy, those who had fewer prenatal consults and those who underwent a caesarian.

Interpretation of these results must consider that this was a single approach, with a significantrecall period. However, it is reasonable to assume that, if 
there had been a recallerror, this would have affected all the women equally. Furthermore, the design used for this study is not the best for inferring causality, in so far as it measuresexposure and the outcome simultaneously. Its use however is justified by the potential to aid public policy in health. Although the classification of late preterm birth does not depend on a single criterion, for nine out of ten womenthis information was obtained from the Pregnancy Card, with $80 \%$ referring to ultrasound examinations between the $6^{\text {th }}$ and $20^{\text {th }}$ week of gestation, the most adequate parameter for determining gestational age, 13,14 and around $10 \%$ depending on the date of last menstruation obtained from the card used at consults. Finally, it is important to recall that this was a population-based study with a low percentage of losses (3\%).

The occurrence of late preterm birth is variable and more common in developing countries, ${ }^{2}$ varyingfrom $4.9 \%$ in Spain 16 to $12.0 \%$ in Venezuela. 17 In Brazil, rates of $10.6 \%$ were found for the city of São Paulo and $11.3 \%$ for Pelotas. 8,10 Comparison of the results of studies is hampered by the different methods used to determine gestational age. It is worth noting, however, that, in all these studies, regardless of the rate of occurrence, around $70 \%$ of birthsare late preterm.

In the present study, black women presented a $\mathrm{PR}$ around $40 \%$ greater for having late preterm children compared to white women. This finding is consistent with other states.10,16,18,19 However, according toVictora et al.,20 it is possible that this pattern of difference for skin color is due to socioeconomic barriers and not only household income. The greatest difficulty with accessing health services may, for example, be due to pregnant women living in very remote locations, which results both in greater transport costs and in more working hours lost to consults. ${ }^{20}$ This was not assessed by the present study. There is thus a need to investigate these aspects of studies that demonstrate inequality in relation to the skin color of the mother.

The larger the number of prenatal consults, the lower the probability of the occurrence of late preterm birth. Mothers who attended less than six prenatal consults had $\mathrm{PR}=1.74$ for late preterm birth in relation to those who attended nine or more. This result is in accordance with that found in a 2004 cohort in Pelotas, where the relative risk was 2.4 when comparing those who attended no prenatal sessions with those who attended seven or more. ${ }^{21}$ It should be borne in mind that, in cases of preterm birth, the number of consults is necessarily lower compared to term births. These women remain preg- nant longer and it is thus to be supposed that they attend a larger number of consults. It is any way clear that the number of consults had a significant impact of the probability of occurrence of late preterm birth, as is to be expected given the benefits of this kind of medical care. This confirms the need to stress the importance of neonatal consults as a procedure that helps to reduce the occurrence of late preterm birth in this locality.

The women who reported depression during pregnancy had a $36 \%$ greater risk of late preterm birth. Stressincreases the concentration of cortisol in the organism. An excess of this hormone increases the risk of preterm birth. ${ }^{22}$ Furthermore, women with untreated depression during pregnancy may have greater difficulty following medical advice, attend prenatal consults less frequently and have a heightened risk of use of alcohol, tobacco and other drugs. 23,24

Mothers undergoing caesarian had a greater prevalence ratio for late preterm children. This may be related to errors in definition of gestational age and the occurrence of caesarian on demand, scheduled in advance at the request of the mother. 25 According to the WHO, the number of caesarians shouldnot exceed $15 \%$ of total births, 26 although, in Brazil, around half of all births are caesarians and, in private hospitals, the figure may be as high as $100 \% .27$ In an effort to combatthis important public health problem, in 2015, theMinistry of Healthand the WHOissued guidelines for women, health professionals and managers, with a view to reducing the number of caesarians in the country.28,29

The results presented hereshow a high frequency of late preterm birth. Unexpectedly, maternal schooling $(p=0.343)$ and household incomewere not associated with the outcome, suggesting that other indicators are more powerfully influencing this occurrence. The care provided during the prenatal period merits special note, since a large number of consultswas found to have an independent effect on reducing the risk of late preterm births. Furthermore, the relatively high prevalence of caesarians appears to be significantly associated with late preterm births. The findings need to be investigated further in other population-based studies, with a larger sample sizeand, if possible, more powerful design, such as cohort studies, so as to establish the causality of these associations and help prevent late preterm births. 


\section{References}

1. Howson CP, Kinney MV, Lawn JE. Born too soon: the global action report on preterm birth. Geneva: World Health Organization; 2012.

2. Blencowe H, Cousens S, Oestergaard MZ, Chou D, Moller A-B, Narwal R, et al. National, regional, and worldwide estimates of preterm birth rates in the year 2010 with time trends since 1990 for selected countries: a systematic analysis and implications. Lancet. 2012; 379: 2162-72.

3. Unicef (Fundo das Nações Unidas para a Infância). Consultoria: pesquisa para estimar a prevalência de nascimentos pré-termo no Brasil e explorar possíveis causas. [acesso em Ago 2015]. 2013. Disponível em: http://www.unicef.org/brazil/pt/resources_27450.htm.

4. Fuchs K, Wapner R. Elective cesarean section and induction and their impact on late preterm births. Clin Perinatol. 2006; 33 (4): 793-801.

5. Engle WA. A Recommendation for the Definition of "Late Preterm" (Near-Term) and the Birth Weight-Gestational Age Classification System. Semin Perinatol. 2006; 30 (1) $2-7$

6. McIntire DD, Leveno KJ. Neonatal Mortality and Morbidity Rates in Late Preterm Births Compared With Births at Term. Obstet Gynecol. 2008; 111 (1): 35-41.

7. Gyamfi-Bannerman C, Ananth CV. Trends in spontaneous and indicated preterm delivery among singleton gestations in the United States, 2005-2012. Obstet Gynecol. 2014 124 (6): 1069-74.

8. Machado Jr LC, Passini Jr R, Rosa IR, Carvalho HB. Neonatal outcomes of late preterm and early term birth. Eur J Obstet Gynecol Reprod Biol. 2014; 179: 204-8.

9. Ananth CV, Friedman AM, Gyamfi-Bannerman C. Epidemiology of moderate preterm, late preterm and early term delivery. Clin Perinatol. 2013; 40 (4): 601-10.

10. Santos IS, Matijasevich A, Domingues MR, Barros AJD, Victora CG, Barros FC. Late preterm birth is a risk factor for growth faltering in early childhood: a cohort study. BMC Pediatr. 2009; 9 (1): 71.

11. IBGE. Estimativas da população residente nos municípios brasileiros com data de referência de $1^{\circ}$ de Julho de 2014 [database on the Internet]. 2014; Disponível em: http://www.ibge.gov.br/home/estatistica/populacao/estimativa2014/

12. FEE/RS. Fundação de Economia e Estatística Siegfried Emanuel Heuser. [acesso em Jan 2015]. Disponível em: $<$ http://www.fee.rs.gov.br/perfil-socioeconomico/municipios/detalhe/?municipio $=$ Rio + Grande $>$

13. National Institute of Health and Care Excellence. Antenatal Care. Routine care for the healthy pregnant woman London: National Institute for Health Care Excellence; 2008

14. Pereira A, Leal MDC, Gama SD, Domingues R, Schilithz A, Bastos M. Determinação da idade gestacional com base em informações do estudo Nascer no Brasil. Cad Saúde
Pública. 2014; 30: 59-70.

15. Brasil. Ministério da Saúde. DATASUS. [acesso em Mar 2016]. Disponível em: http://www2.datasus.gov.br/ DATASUS/index.php?area $=060702$

16. Carter M, Fowler S, Holden A, Xenakis E, Dudley D. The late preterm birth rate and its association with comorbidities in a population-based study. Am J Perinatol. 2011; 28 (9): 703-8.

17. Furzan J, Sanchez H. Recién nacido prematuro tardío: incidencia y morbilidad neonatal precoz. Arch Venez Pueric Pediatr. 2009; 72 (2): 59-67.

18. Morse SB, Zheng H, Tang Y, Roth J. Early school-age outcomes of late preterm infants. Pediatrics. 2009; 123 (4): $622-9$.

19. Murthy K, Holl JL, Lee TA, Grobman WA. National trends and racial differences in late preterm induction. Am J Obstet Gynecol. 2011; 205 (5): 458.e1-.e7.

20. Victora CG, Matijasevich A, Silveira MF, Santos IS, Barros AJD, Barros, FC. Socio-economic and ethnic group inequities in antenatal care quality in the public and private sector in Brazil. Health Policy Plann. 2010; 25 (4): 253-61.

21. Santos IS, Matijasevich A, Silveira MF, Sclowitz IKT, Barros AJD, Victora CG, et al. Associated factors and consequences of late preterm births: results from the 2004 Pelotas birth cohort. Paediatr Perinat Epidemiol. 2008; 22 (4): 350-9.

22. Entringer S, Buss C, Andersen J, Chicz-DeMet A, Wadhwa PD. Ecological momentary assessment of maternal cortisol profiles over a multiple-day period predicts the length of human gestation. Psychosom Med. 2011; 73 (6): 469-74.

23. Carvalho PID, Pereira PMH, Frias PGD, Vidal SA, Figueiroa JN. Fatores de risco para mortalidade neonatal em coorte hospitalar de nascidos vivos. Epidemiol Serv Saúde. 2007; 16: 185-94.

24. Hendrick V, Smith LM, Hwang S, Altshuler LL, Haynes D. Weight gain in breastfed infants of mothers taking antidepressant medications. J Clin Psychiatry. 2003; 64 (4): 4102.

25. Victora CG, Aquino EML, Leal MC, Monteiro CA, Barros FC, Szwarcwald CL. Maternal and child health in Brazil: progress and challenges. Lancet. 2011; 377: 1863-76.

26. WHO (World Health Organization). Appropriate Technology for birth. Lancet. 1985; 8452: 436-7.

27. ANS (Agência Nacional de Saúde Suplementar). Direito de informação da gestante e obrigatoriedade do cartão da gestante, cartão de informação e partograma na saúde suplementar. Rio de Janeiro. Agência Nacional de Saúde Suplementar; 2014. [acesso em Ago 2015]. Disponível em: http://www.ans.gov.br/imagens/stories/Participação_da_soc iedade/consultas_publicas/cp5556/nota703.pdf.

28. WHO (World Health Organization). Declaração da OMS sobre Taxas de Cesáreas. Geneva; 2015. [acesso em Ago 2015]. Disponível: http://apps.who.int/iris/bitstream/ 10665/161442/3/WHO_RHR_15.02_por.pdf?ua=1\&ua=1. 
29. Brasil. Ministério da Saúde. Secretaria de educação à saúde. Diretrizes de Atenção à Gestante: a Operação Cesariana. Brasilia, DF; 2015. [acesso em Ago 2015].

Disponível em:http://conitec.gov.br/images/Consultas/

Relatorios/2015/Relatorio_PCDTCesariana_CP.pdf.

Received on november 18, 2015

Final version submitted on march 29, 2016

Approved on april 1, 2016 